\title{
Medullary Hemorrhage that Preceded the Onset of Multiple Cavernous Angiomas
}

\author{
Tameto Naoi ${ }^{1}$, Koichi Nakao ${ }^{2}$, Yuko Nakamura ${ }^{1}$, Ayako Ando ${ }^{1}$ and Tadataka Kawakami ${ }^{1}$
}

\begin{abstract}
Medullary hemorrhage is rare, and the causative role of hypertension still remains controversial. Cavernous angioma and other vascular malformations have been reported to cause medullary hemorrhage. A 53-year-old man was admitted to our hospital for vertigo. Medullary hemorrhage and multiple small hypointense lesions were detected on T2-star weighted magnetic resonance imaging (T2*W MRI). One and four months later, the appearance of new lesions confirmed the diagnosis of cerebral cavernous angioma. Cavernous angioma is often characterized by de novo appearance/progression on MRI. A follow-up MRI is required to diagnose cavernous angioma in patients with medullary hemorrhage.
\end{abstract}

Key words: medulla oblongata, medullary hemorrhage, cavernous angioma, vascular malformation, T2-star weighted magnetic resonance imaging

(Intern Med 54: 843-846, 2015)

(DOI: 10.2169/internalmedicine.54.3657)

\section{Introduction}

Medullary hemorrhage is a rare event with poorly defined epidemiology (1-5). Medullary hemorrhage has been reported to occur in the young and elderly $(1,3,6)$, as pointed out by Cantu et al., "medullary hemorrhage has no age predilection" (1). Interestingly, the causative role of hypertension is controversial, and vascular malformations are often detected in patients with medullary hemorrhage $(4,5)$, with cavernous angioma being a representative disease $(1,7)$. However, cavernous angiomas are rarely detected on angiography, called "occult vascular malformations" $(8,9)$. Rather, these angiomas are found on magnetic resonance imaging (MRI), including T2-star weighted $(\mathrm{T} 2 * \mathrm{~W})$ sequences $(9,10)$. Before the development of MRI, cavernous angiomas may have been overlooked in cases of idiopathic medullary hemorrhage. In this report, we present a rare case of idiopathic medullary hemorrhage later found to be caused by a cavernous angioma.

\section{Case Report}

A 53-year-old man with well-controlled hypertension was admitted to our hospital for the sudden onset of vertigo and gait disturbance. A physical examination showed normal vital signs, except for high blood pressure (190/81 mmHg). A neurological examination showed vertigo, mild dysphagia, hiccups, mild left hemiparesis and dysesthesia on the right side of the patient's body, including his face. Brain computed tomography (CT) and T2*W MRI showed hemorrhage in the medulla oblongata, which explained these symptoms (Fig. 1A, B). In addition, T2*W MRI revealed multiple small hypointense lesions in other areas, namely the cerebellar hemisphere, pons and middle cerebellar peduncle (Fig. 1C). These lesions were observed only on $\mathrm{T} 2 * \mathrm{~W}$ MRI and exhibited features suggestive of cerebral microbleeds. Fluid-attenuated inversion recovery (FLAIR) imaging showed no leukoaraiosis, and magnetic resonance angiography (MRA) demonstrated no evidence of vascular malformation. Laboratory testing disclosed the following findings: hemoglobin: $11.7 \mathrm{~g} / \mathrm{dL}$, platelet count: $24.8 \times 10^{4} /$ $\mu \mathrm{L}$, blood urea nitrogen: $11.3 \mathrm{mg} / \mathrm{dL}$, creatinine: $0.82 \mathrm{~g} / \mathrm{dL}$,

${ }^{1}$ Division of Neurology, Department of Internal Medicine, Shin-Oyama City Hospital, Japan and ${ }^{2}$ Division of Neurology, Department of Internal Medicine, Junwakai Memorial Hospital, Japan

Received for publication July 10, 2014; Accepted for publication September 1, 2014

Correspondence to Dr. Tameto Naoi, sph89vz9@coda.ocn.ne.jp 

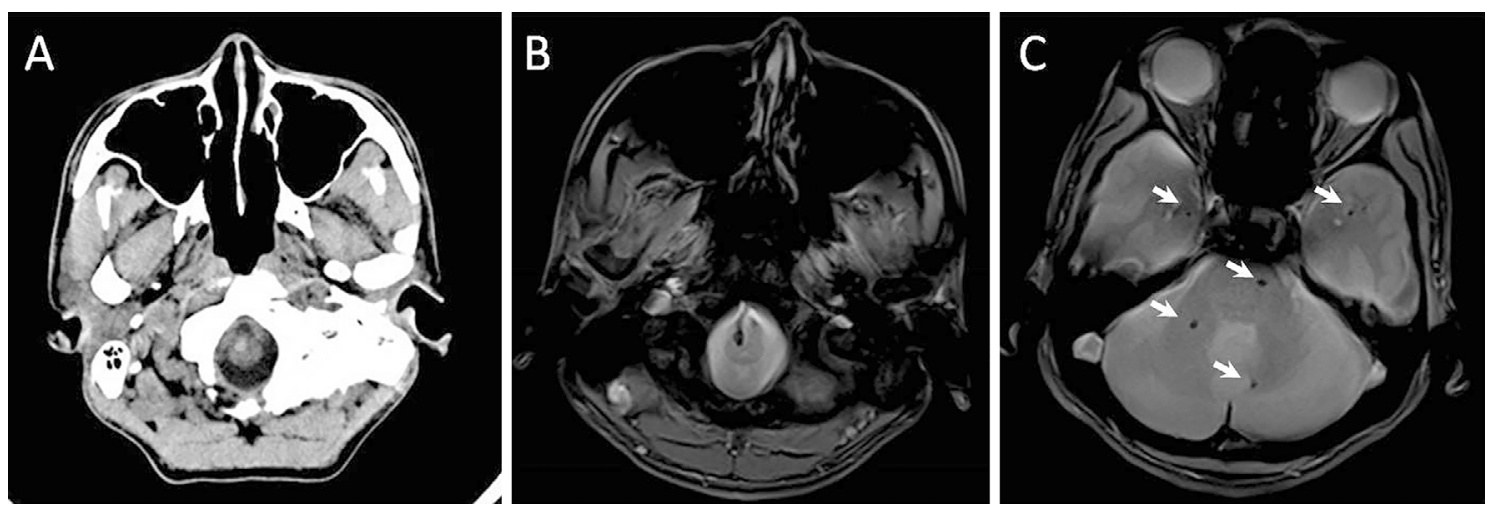

Figure 1. Brain imaging of the patient on admission. (A) Brain axial CT showed hemorrhage in the medulla oblongata. (B) Brain axial T2*W MRI showed hemorrhage at the same site as in panel A. (C) Multiple hypointense lesions in the pons, right middle cerebellar peduncle, left cerebellar hemisphere and both temporal lobes on T2*W MRI (arrows).
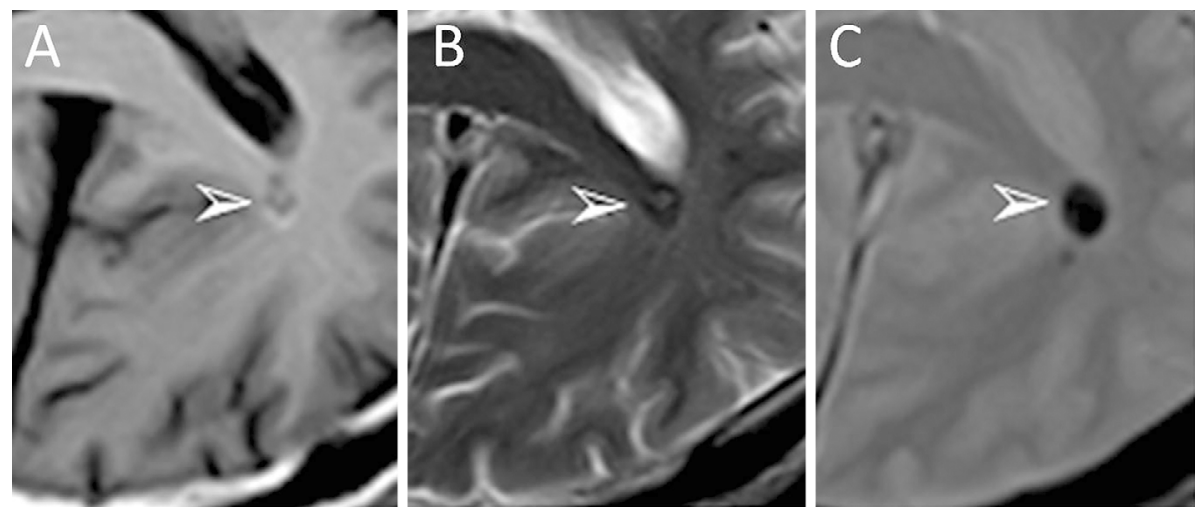

Figure 2. Follow-up MRI performed one month later. (A) T1W MRI. (B) T2W MRI. (C) T2*W MRI. The lesion exhibited a hyperintense signal within the hypointense rim on T1/T2W MRI (arrowhead) and is easily detected on T2*W MRI.

creatinine clearance: $78 \mathrm{~mL} / \mathrm{min}$, PT-INR: 1.08 and APTT: 28.3 s. A transthoracic echocardiogram revealed no abnormalities. The patient's symptoms gradually improved under conservative treatment and rehabilitation. A neurological examination showed no deficits, except for dizziness. Therefore, he was discharged on hospital day 35 .

One month later, follow-up MRI showed the detailed appearance of a cerebral microbleed-like lesion (Fig. 2). Four months later, another obvious lesion was detected in the midbrain tegmentum (Fig. 3), which subsequently ruptured 18 months later (Figure not shown). Nine months later, the patient presented with a high level of plasma transforming growth factor $\beta 1$ (TGF- $\beta 1$ : $4.26 \mathrm{ng} / \mathrm{mL}$; normal range: $0.89 \pm 1.80 \mathrm{ng} / \mathrm{mL}$ ); the plasma vascular endothelial growth factor (VEGF) level was $5.09 \mathrm{pg} / \mathrm{mL}$ (normal control: $<38.3$ $\mathrm{pg} / \mathrm{mL})$.

\section{Discussion}

Medullary hemorrhage is a rare event, and its epidemiology is not well known (1-5). In the present case, the etiology of medullary hemorrhage was unclear on initial MRI.
However, the appearance of two lesions allowed for the diagnosis of multiple cavernous angiomas (Fig. 2, 3). The medullary hemorrhage was possibly caused by the rupture of an angioma in the medulla oblongata, although MRI was not performed before the event. Cavernous angioma is often characterized by de novo appearance/progression on MRI.

MRI has diagnostic utility. Zabramski et al. radiologically classified typical cavernous angioma [Table (11)]. According to this classification, the lesion (Fig. 2) in this case is a type I cavernous angioma, and the hypointense rim is considered to be the result of hemosiderin or iron deposition. Another lesion (Fig. 3) is difficult to classify because its shape changed on each MRI scan; this lesion ruptured after 18 months. Brainstem cavernous angioma carries a higher risk of bleeding and rebleeding than supratentorial cavernous angioma, and over $60 \%$ of midbrain cavernous angiomas are detected in the midbrain tegmentum (12).

The presence of multiple small hypointense lesions on initial T2*W MRI (Fig. 1C, arrows) may be retrospectively diagnosed as type IV cavernous angiomas. Using $\mathrm{T} 2 * \mathrm{~W}$ MRI is important because type IV lesions are detectable only on $\mathrm{T} 2 * \mathrm{~W}$ MRI. In addition, it is easier to identify cav- 

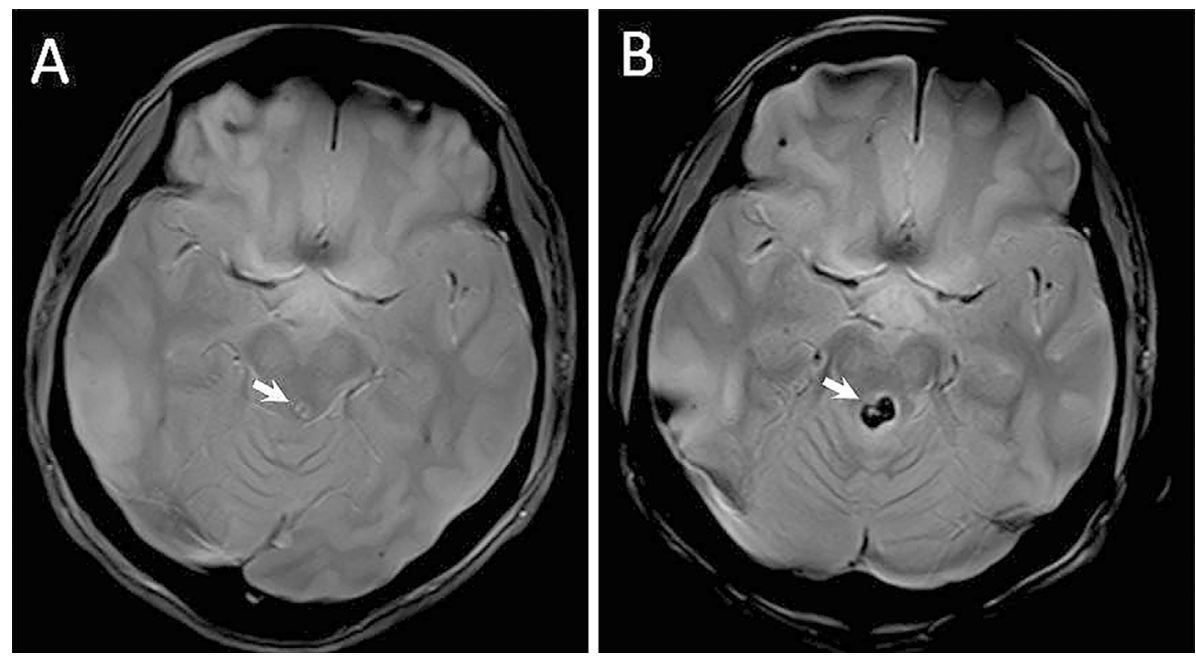

Figure 3. (A) Initial T2*W MRI. A small lesion with a hypointense rim in the midbrain tegmentum (arrow). (B) Follow-up MRI four months later. Progression of the lesion is visible (arrow), and the lesion has a hyperintense core.

Table. MRI Imaging Classification for Cavernous Angioma (Zabramski et al.)

\begin{tabular}{|c|c|}
\hline Lesion type & MRI signal characteristic * \\
\hline Type I & $\begin{array}{l}\text { T1: hyperintense core } \\
\text { T2: hyper- or hypointense } \\
\text { core with surrounding } \\
\text { hypointense rim }\end{array}$ \\
\hline Type II & $\begin{array}{l}\text { T1: reticulated mixed signal core } \\
\text { T2: reticulated mixed signal core } \\
\text { with sorrounding hypointense rim }\end{array}$ \\
\hline Type III & $\begin{array}{l}\text { T1: iso- or hypointense } \\
\text { T2: hypointense with a hypointense rim } \\
\text { that magnifies the size of the lesion } \\
\text { GE: hypointense with greater magnification than } \mathrm{T} 2\end{array}$ \\
\hline Type IV & $\begin{array}{l}\mathrm{T} 1 \text { : poorly seen or not visualized at all } \\
\mathrm{T} 2 \text { : poorly seen or not visualized at all } \\
\text { GE: punctuate hypointense lesions }\end{array}$ \\
\hline
\end{tabular}

ernous angiomas on $\mathrm{T} 2 * \mathrm{~W}$ MRI than on $\mathrm{T} 1 \mathrm{~W}$ or $\mathrm{T} 2 \mathrm{~W}$ MRI $(9,10)$. The use of standard MRI without $\mathrm{T} 2 * \mathrm{~W}$ sequences increases the potential for overlooking lesions.

However, the identification of type IV cavernous angioma is associated with several problems, as small hypointense lesions on $\mathrm{T} 2 * \mathrm{~W}$ MRI may also be diagnosed as cerebral microbleeds, which are primarily caused by hypertension or amyloid angiopathy. Furthermore, hypertension or amyloid angiopathy should be considered in the differential diagnosis because these conditions frequently result in intracranial hemorrhage.

Distinguishing microbleeds and type IV cavernous angiomas is difficult, as cavernous angiomas sometimes mimic microbleeds (13). The diagnosis of cerebral microbleeds often depends on the age of the patient and the distribution of the lesion. The current patient was too young for the development of amyloid angiopathy. In addition, his hypertension was well controlled, and MRI showed neither microbleeds in the basal ganglia nor small-vessel changes in the deep white matter. Moreover, there was no evidence of hypertensive changes, such as retinopathy or left ventricular hypertrophy.

The pathophysiology underlying the rare occurrence of hypertensive medullary hemorrhage has yet to be elucidated. Anatomically, hypertensive intracranial hemorrhage is explained by the rupture of microaneurysms, as observed in the basal ganglia, pons or cerebellum (14). However, autopsy studies have demonstrated the absence of microaneurysms in the medulla oblongata in such cases $(14,15)$. These results suggest that the arteries that supply medulla oblongata are less affected by hypertension than those in other areas.

In the present case, the plasma TGF- $\beta 1$ level increased nine months after medullary hemorrhage. The detection of high plasma TGF- $\beta 1$ and VEGF levels may support the diagnosis of cavernous angioma (16), and TGF- $\beta 1$ and VEGF regulate angiogenesis. In addition, previous studies have shown that TGF- $\beta 1$ and VEGF are overexpressed in cavernous angiomas $(17,18)$. However, the association between TGF- $\beta 1$ and the disease activity was unclear in this case.

The appearance of new lesions one and four months later confirmed the diagnosis of cavernous angioma in this case. In a Korean case report, cavernous angioma was detected three months after medullary hemorrhage (7). Therefore, even if cavernous angiomas are not diagnosed on the initial MRI examination, follow-up MRI is required to detect the de novo appearance or progression to typical cavernous angioma in patients with medullary hemorrhage.

The authors state that they have no Conflict of Interest (COI).

\section{References}

1. Barinagarrementeria F, Cantú C. Primary medullary hemorrhage. Report of four cases and review of the literature. Stroke 25: 1684- 
1687, 1994.

2. Mastaglia FL, Edis B, Kakulas BA. Medullary hemorrhage: a report of two cases. J Neurol Neurosurg Psychiatry 32: 221-225, 1969.

3. Naseem M, Zachariah SB, Stone J, Russell E. Cervicomedullary hematoma: diagnosis by MR. Am J Neuroradiol 7: 1096-1098, 1986.

4. Kase CS, Mohr JP, Caplan LR. Intracerebral hemorrhage. In: Stroke: Pathophysiology, Diagnosis and Management. 2nd ed. Barnet HJM, Mohr JP, Stein BM, Yatsu FM, Eds. Churchill Livingstone, New York, 1992: 561-616.

5. Caplan LR. Intracerebral hemorrhage. In: Caplan's Stroke: a Clinical Approach. 4th ed. Caplan LR, Ed. Saunders Elsevier, 2009: 487-522.

6. Kempe LG. Surgical removal of an intramedullary haematoma simulating Wallenberg's syndrome. J Neurol Neurosurg Psychiatry 27: 78-80, 1964.

7. Yang HD, Lee KH. Medullary hemorrhage after ischemic Wallenberg's syndrome in a patient with cavernous angioma. J Clin Neurol 6: 221-223, 2010.

8. Davis DH, Kelly PJ. Stereotactic resection of occult vascular malformations. J Neurosurg 72: 698-702, 1990.

9. Lehnhardt FG, von Smekal U, Rückriem B, et al. Value of gradient-echo magnetic resonance imaging in the diagnosis of familial cerebral cavernous malformation. Arch Neurol 62: 653-658, 2005

10. Labauge P, Laberge S, Brunereau L, Levy C, Tournier-Lasserve E.
Hereditary cerebral cavernous angiomas: clinical and genetic features in 57 French families. Société Française de Neurochirurgie. Lancet 352: 1892-1897, 1998.

11. Zabramski JM, Wascher TM, Spetzler RF, et al. The natural history of familial cavernous malformations: results of an ongoing study. J Neurosurg 80: 422-432, 1994.

12. Fritschi JA, Reulen HJ, Spetzler RF, Zabramski JM. Cavernous malformations of the brain stem. A review of 139 cases. Acta Neurochir (Wien) 130: 35-46, 1994.

13. Greenberg SM, Vernooij MW, Cordonnier C, et al. Cerebral microbleeds: a guide to detection and interpretation. Lancet Neurol 8: 165-174, 2009.

14. Cole FM, Yates P. The occurrence and significance of intracerebral microaneurysms. J Pathol Bact 93: 393-411, 1967.

15. Kanai H, Yamada K, Yoshida Y. Histological and morphometrical studies on small arteries in normal brainstems with special reference to the pathogenesis of the hypertensive brainstem hemorrhage. No to Shinkei 50: 637-642, 1998.

16. Abe $\mathrm{T}$, Morishige $\mathrm{M}$, Ooba $\mathrm{H}$, et al. The association between high VEGF levels and multiple probable punctuate cavernous malformations. Acta Neurochir (Wien) 151: 855-859, 2009.

17. Maiuri F, Cappabianca $P$, Gangemi M, et al. Clinical progression and familial occurrence of cerebral cavernous angiomas: the role of angiogenic and growth factors. Neurosurg Focus 21: e3, 2006.

18. Kiliç T, Pamir MN, Küllü S, Eren F, Ozek MM, Black PM. Expression of structural proteins and angiogenic factors in cerebrovascular anomalies. Neurosurgery 46: 1179-1191, 2000.

(C) 2015 The Japanese Society of Internal Medicine http://www.naika.or.jp/imonline/index.html 